\title{
Diagnóstico Adaptativo e Individualização em Gêmeos: Estudo Exploratório
}

\author{
Maria Elizabeth Barreto Tavares dos Reis \\ Universidade Estadual de Londrina, PR, Brasil. \\ Sílvia Nogueira Cordeiro \\ Universidade Estadual de Londrina, PR, Brasil. \\ Ryad Simon \\ Universidade de São Paulo, SP, Brasil.
}

Resumo: O amadurecimento afetivo-emocional implica o desenvolvimento da própria individualidade. Todavia, o processo de individualização em gêmeos é mais complexo do que o vivenciado por singulares, pois necessitam separar-se não apenas da mãe, mas também do cogêmeo. O presente trabalho teve o objetivo de estudar a capacidade de adaptação e relacioná-la aos processos de separação e individualização em gêmeos. Participaram 12 pares de gêmeos adultos do mesmo sexo, que foram entrevistados a respeito das histórias de vida e avaliados por meio da Escala Diagnóstica Adaptativa Operacionalizada Revisada. A análise de dados consistiu em relacionar o diagnóstico adaptativo com o processo de individualização vivenciado pelos cogêmeos ao longo da vida. Verificou-se que a maneira com que os cogêmeos foram percebidos, identificados e atendidos em suas necessidades específicas contribuiu significativamente para que a individualização e adaptação aos diversos setores da vida pudessem ou não ocorrer de forma eficaz. Os próprios gêmeos sugerem que pais e educadores tratem os cogêmeos como pessoas diferentes e procurem perceber as características individuais de cada cogêmeo.

Palavras-chave: Adaptação, EDAO, Gêmeos, Individuação.

\section{Adaptive Diagnosis and Individualization in Twins: an Exploratory Study}

\begin{abstract}
Affective and emotional maturation implies the evolving of individualityitself. However, the individualization process in twins is more complex than the one experienced by singles because they need to separate not only from the mother but also from the co-twin. This research aimed to study the adaptive capacity in twins and relate it to their processes of separation and individualization. 12 pairs of same sex adult twins participated, who were interviewed about their life stories and evaluated by EDAO-R (Adaptive Operational Diagnostic Scale - Revised). Data analysis consisted in relating the adaptive diagnosis with the individualization process experienced by co-twins. It was found that the way the co-twins were perceived, identified and assisted in their specific needs significantly has contributed to the effectiveness (or not) of their individualization and adaptation to the various sectors of life. The twins themselves suggest that parents and educators treat co-twins as different persons and seek to understand the individual characteristics of each of them.
\end{abstract}

Keywords: Adaptation, EDAO, Twins, Individuation. 


\title{
Diagnóstico Adaptativo e Individualización en Gemelos: Un Estudio Exploratório
}

\begin{abstract}
Resumen: La madurez afectiva y emocional implica el desarrollo de la individualidad. Sin embargo, el proceso de individualización en gemelos es más complejo que la experimentada por los no-gemelos, ya que necesitan separarse no solamente de la madre sino también de su co-gemelo. Este estudio tuvo como objetivo estudiar la capacidad de adaptación y relacionarlas a los procesos de separación e individuación en gemelos. Participaron 12 pares de gemelos adultos del mismo sexo que fueron entrevistados acerca de las historias de vida y evaluadas por EDAO-R (Escala Diagnostica Adaptativa Operable Revisada). El análisis de datos se basó en relacionar el diagnóstico de adaptación con el proceso de individualización experimentada por co-gemelos a lo largo de sus vidas. Fue identificado que la forma en que fueron percibidos, identificados y asistidos en sus necesidades específicas contribuyó significativamente para que la individualización y la adaptación a diferentes ámbitos de la vida pudiesen o no ocurrir de manera efectiva. Los gemelos sugieren que los padres y educadores traten co- gemelos como diferentes personas y entiendan las características individuales de cada co- gemelo.
\end{abstract}

Palabras clave: Adaptación, EDAO, Gemelos, Individuación.

\section{Introdução}

Ao nascer, os bebês vivem em estado simbiótico com as respectivas mães e necessitam se separar dela para desenvolver as suas próprias identidades, tema bastante estudado pela Psicologia e Psicanálise. Entretanto, por partilhar a companhia do cogêmeo e as atenções da mãe desde o início da vida, o processo de individualização em gêmeos apresenta uma complexidade diferente daquela envolvida nas relações entre a mãe e o filho singular. Winnicott (1964/1982) considerava impossível a mãe satisfazer as necessidades dos dois filhos simultaneamente, mas enfatizou que a mãe deveria tratar cada filho como ser único, reconhecendo-os como diferentes entre si e mantendo uma relação total. No início da vida, a mãe "suficientemente boa" deve ser capaz de atender as necessidades do bebê favorecendo até uma "breve experiência de onipotência” (Winnicott, 1963/1983, p. 55), sendo que, mais tarde, a mesma mãe deve falhar para que o bebê consiga se adaptar às exigências do ambiente, sem contar com a presença constante da mãe como ego auxiliar. Além disso, o fato da mãe não funcionar de forma suficientemente boa pode levar a dificuldades ou distorções no processo de amadurecimento do ego do bebê. Por outro lado, Scalco e Donelli (2014) ressaltaram também a maior capacidade de entrega necessária à mãe de gêmeos e a possibilidade de manifestação de sintomas quando a relação mãe-bebê não proporcione o amparo psíquico adequado às demandas dos bebês. Entretanto, necessário se faz considerar também a maior disponibilidade interna que a mãe de gêmeos precisa ter.

$\mathrm{Na}$ atualidade, são encontrados alguns estudos sobre a maneira como os pais cuidam dos gêmeos (Reis, 2015; Scalco, \& Donelli, 2014; Vieira, \& Branco, 2010) e como são afetados por cuidar de filhos gêmeos (Andrade, Martins, Angelo, \& Martinho, 2014), mas raramente, como os próprios gêmeos se percebem (Cerrut, Prino, \& Quaglia, 2008). Desde o início da vida, os gêmeos vivenciam situações diferentes dos singulares. O nascimento de um novo irmão é motivo de preocupação para as crianças que nascem sozinhas, enquanto os gêmeos têm o irmão gêmeo desde sempre e podem muito cedo perceber que, em dados momentos, é o outro quem exerce a posse da sua mãe (Winnicott, 1964/1982), fato mencionado também por autores como Athanassiou (1986) e Reis (2015). Podemos aqui conjecturar que, se o complexo de Édipo se instala quando o bebê percebe o pai como um terceiro, no casos de gêmeos, o cogêmeo pode ser considerado um terceiro; neste sentido, o complexo de Édipo vivenciado pelos gêmeos implica questões mais complexas do que nos singulares (Reis, 2015).

Gêmeos com poucos meses de vida podem utilizar estratégias para atrair a atenção e os cuidados maternos quando o foco da mãe é o cogêmeo (Reis, 
2015). Em pesquisa realizada com crianças de 4 a 6 anos a respeito da imagem de si mesmas por meio desenhos de figura humana (Cerruti et al., 2008), verificou-se que, nos pares monozigóticos, cada cogêmeo desenhava a si mesmo e ao cogêmeo com algum detalhe que os diferenciava, enquanto nos dizigóticos as figuras eram desenhadas de forma mais parecida. Considerando que a criança que desenha representa não o que vê, mas formula uma imagem do desejo, os autores acreditam que os gêmeos monozigóticos estariam demonstrando que precisam diferenciar-se em função da necessidade de individuação. Tais estudos sugerem que, desde muito cedo, as crianças gêmeas demonstram a necessidade de serem percebidas de acordo com suas características individuais.

Em pesquisa a respeito das crenças, ideias e expectativas dos cuidadores (mãe, professora e avô) em relação aos gêmeos, Vieira e Branco (2010) enfatizaram que deveriam viabilizar oportunidades em que o processo de individuação e valoração da individualidade - não de individualismo - fossem incentivadas.

Os pais devem respeitar as diferenças individuais, favorecendo a "tomada de consciência de que existe um 'nós' (duas crianças) e um 'eu' (uma criança somente); assim não é favorável tratá-los como um bloco único, mas como dois seres com personalidades próprias" (David, Azevedo, Russi, Berthoud, \& Oliveira, 2000, p. 62). Entretanto, nem sempre isso acontece, como pode ser verificado em alguns pares de bebês gêmeos estudados por Reis (2015): em um dos casos, os pais utilizavam os mesmos apelidos para ambos cogêmeos e os vestiam com roupas sempre idênticas; em outro, os nomes das crianças praticamente nunca eram pronunciados, situação que culminou em dificuldades de autoidentificação tão importantes que, aos quatro anos, um dos cogêmeos não sabia qual dos nomes era o seu.

Embora vários autores enfatizem a necessidade de trabalhos psicoprofiláticos e de orientação familiar a fim de contribuir para um processo de vinculação mais satisfatório e, consequentemente, desenvolvimento mais saudável das crianças, praticamente inexistem trabalhos a respeito da saúde psicológica de gêmeos adultos relacionados ao processo de individuação, principalmente a partir de relatos dos próprios gêmeos (Määttä, Päiveröinen, Määttä, \& Uusiautti, 2016).

A partir da revisão da literatura observa-se que os gêmeos enfrentam situações diferentes dos singulares no seu dia a dia; portanto, é possível questionar se poderia haver comprometimento da saúde psicológica dos cogêmeos em função das peculiaridades do processo de individualização.

A Escala Diagnóstica Adaptativa Operacionalizada (EDAO), idealizada por Simon (1989, 1997, 2005) como estratégia para realizar o diagnóstico precoce e preventivo em Saúde Mental, tem sido utilizada pelo próprio autor, bem como por outros pesquisadores (Honda, \& Yoshida, 2013; Simon, \& Yamamoto, 2009; Yoshida, Bardagi, \& Honda, 2015), como forma de diagnosticar e planejar estratégias de prevenção e tratamento psicológico.

A EDAO avalia os indivíduos de acordo com a sua capacidade de adaptação, a qual é considerada por Simon (2005) como um conceito que possibilita a avaliação funcional de aspectos psíquicos vivenciados no passado e no presente, além de favorecer a elaboração de um prognóstico futuro. A adaptação é inerente à permanência da vida, podendo alternar períodos de estabilidade e de crise. A "condição adaptativa do sujeito consiste no estado de integração de seus vários sistemas e coerência de suas ações com os objetivos de viver melhor, podendo ser verificáveis por meio de comportamentos observáveis e comunicáveis" (Santos, Honda, Santeiro, \& Yoshida, 2013, p. 85). A EDAO sofreu uma revisão em 1997/1998, passando a ser chamada de Escala Diagnóstica Adaptativa Operacionalizada Revisada (EDAO-R), e tem sido considerada por diversos pesquisadores como um bom instrumento para diagnosticar a adaptação do indivíduo em diferentes contextos (Yoshida, 2013; Yoshida et al., 2015).

De modo geral espera-se que o adulto seja capaz de viver de forma relativamente independente; entretanto, se houver comprometimento do processo de individualização, é provável que apresente dificuldades em estabelecer relações afetivas e exercer funções produtivas que possibilitem sua manutenção e subsistência. Considerando que gêmeos enfrentam situações diferentes de singulares no seu dia a dia, é possível questionar se haveria comprometimento da saúde mental, em termos de "eficácia adaptativa" (Yoshida, 2013; Yoshida et al., 2015), em função das peculiaridades do processo de individualização de cada cogêmeo.

A adaptação é avaliada por meio de quatro setores: A-R (Afetivo-Relacional), Pr (Produtividade), S-C (Sociocultural) e Or (Orgânico). Inicialmente são realizadas entrevistas clínicas, semidirecionadas a temas específicos; posteriormente, as respostas são analisadas qualitativamente. Aos setores A-R e Pr 
são atribuídos escores, enquanto nos demais, S-C e Or, a avaliação é apenas qualitativa. A EDAO-R possibilita diagnosticar cada pessoa em relação a cinco grupos: adaptação Eficaz, caracterizada como grupo 1 e adaptação Ineficaz, que é subdividida em quatro grupos: leve (2), moderada (3), severa (4) e grave (5). Além disso, caso o indivíduo diagnosticado em qualquer das classificações anteriores esteja vivenciando dificuldades vitais para as quais não encontra solução imediata, ele poderá ser considerado em crise (Simon, 2005). A cada um dos grupos de adaptação ineficaz correspondem diferentes graus de sintomas psicopatológicos, possibilitando o encaminhamento para atendimento psicoterápico mais adequado a cada caso, quando necessário.

Tendo em vista o interesse em estudar a saúde mental de gêmeos adultos, optou-se por utilizar a EDAO-R como estratégia de investigação no presente trabalho, com os objetivos estudar a capacidade de adaptação e relacioná-la aos processos de separação e individualização em gêmeos.

\section{Método}

A pesquisa foi realizada numa universidade brasileira por meio de um estudo qualitativo exploratório.

Participaram do estudo 12 pares de gêmeos, com idades entre 25 e 40 anos, consistindo de sete pares masculinos e cinco femininos, sendo que 11 pares se consideravam univitelinos. Os gêmeos foram convidados a participar por meio de mensagens colocadas em rádio, jornais e redes sociais. Todos os participantes concordaram em participar do estudo e assinaram o Termo de Consentimento Livre e Esclarecido, aprovado pelo Comitê de Ética da instituição (Parecer CAAE 13282113.2.0000.5231) onde a pesquisa foi realizada.

$\mathrm{O}$ instrumento utilizado foi um roteiro de entrevista composto por duas etapas distintas, sendo a primeira relativa aos quatro setores avaliados pela EDAO-R (Simon, 1989, 1997, 2005; Yoshida et al., 2015) e a segunda, às peculiaridades da história de vida, questionando se consideravam ter sido percebidos e tratados de forma igual ou diferente pela família ao longo da infância, adolescência e na atualidade, como eram percebidos pelos educadores e colegas de escola, como realizavam as atividades de esporte e lazer, como foram realizadas as escolhas profissionais e se havia interferência do cogêmeo nos diversos setores da sua vida.
A coleta de dados foi realizada por acadêmicos do curso de Psicologia, por meio de entrevistas individuais com duração de aproximadamente uma hora, realizadas com todos os cogêmeos separadamente um em relação ao outro, e em diferentes locais, dependendo da disponibilidade dos entrevistados (residências dos gêmeos, instituições de ensino, locais de trabalho e ambientes públicos).

As entrevistas foram gravadas, transcritas e, posteriormente, categorizadas e analisadas considerando a relação entre o diagnóstico adaptativo e o processo de individualização em gêmeos.

\section{Resultados e discussão}

Verificou-se que 12 cogêmeos apresentaram Adaptação Eficaz, oito cogêmeos apresentaram Adaptação Eficaz em crise, e quatro, Adaptação Ineficaz Leve em crise, de acordo com os critérios da EDAO-R (Simon, 1989, 1997, 2005), como pode ser observado nos Quadros 1 e 2. Para facilitar a análise, os gêmeos foram agrupados considerando os resultados obtidos na EDAO-R.

\section{Ambos os cogêmeos de cada par diagnosticados com Adaptação Eficaz}

Em cinco pares, ambos cogêmeos obtiveram diagnóstico de Adaptação Eficaz, sendo três do sexo feminino (F1A e F1B; F3A e F3B; F6A e F6B) e dois masculinos (M4A e M4B; M5A e M5B). Os cogêmeos de quatro pares eram solteiros e apenas os gêmeos do par M4A e $B$ eram casados. Os quatro pares de cogêmeos tinham aparência muito semelhante e o mesmo nível de escolaridade. Nos cinco pares, as profissões eram diferentes (Quadro 1 e 2). Verificou-se que, em quatro dos cinco pares, os cogêmeos eram percebidos de forma semelhante na infância e adolescência, sendo que os familiares se baseavam em alguma pinta ou marca de nascimento para diferenciá-los. Na vida adulta, apenas um dos pares continuava sendo percebido assim.

$\mathrm{Na}$ infância e adolescência eram vestidos com roupas iguais; entretanto, cada um era proprietário das suas roupas. Todos afirmaram que o seu estilo de vestuário na vida adulta é semelhante ao do cogêmeo; tal fato poderia estar relacionado à maneira como foram criados.

Segundo Bacon (2006, citado por Vieira, \& Branco, 2010), algumas pesquisas demonstram que os pais acreditam que apenas crianças gêmeas mais velhas 
Psicologia: Ciência e Profissão Jan/Mar. 2018 v. 38 n¹, 142-156.

\section{Quadro 1}

Diagnósticos obtidos pelos gêmeos masculinos através da EDAO

\begin{tabular}{|c|c|c|c|c|c|c|}
\hline Gêmeos & Idade & Aparência & Estado civil & Escolaridade & $\begin{array}{c}\text { Profissão } \\
(=\mathrm{ou} \neq)\end{array}$ & Diagnóstico EDAO \\
\hline M1A & 40 & $\begin{array}{c}\text { Pouco } \\
\text { semelhante }\end{array}$ & Casado & Superior Completo & Igual & Adaptação Eficaz em crise \\
\hline M1B & 40 & $\begin{array}{c}\text { Pouco } \\
\text { semelhante }\end{array}$ & Casado & Superior Incompleto & Igual & $\begin{array}{c}\text { Adaptação Ineficaz Leve } \\
\text { em crise }\end{array}$ \\
\hline $\mathrm{M} 2 \mathrm{~A}$ & 31 & Semelhante & Solteiro & Superior Completo & Diferente & Adaptação Eficaz em crise \\
\hline M2B & 31 & Semelhante & Solteiro & Superior Incompleto & Diferente & Adaptação Eficaz em crise \\
\hline M3A & 37 & $\begin{array}{c}\text { Pouco } \\
\text { semelhante }\end{array}$ & Casado & Superior Incompleto & Diferente & Adaptação Eficaz \\
\hline M3B & 37 & $\begin{array}{c}\text { Pouco } \\
\text { semelhante }\end{array}$ & Solteiro & Superior Completo & Diferente & Adaptação Eficaz em crise \\
\hline M4A & 28 & Semelhante & Casado & Superior Completo & Diferente & Adaptação Eficaz \\
\hline M4B & 28 & Semelhante & Casado & Superior Incompleto & Diferente & Adaptação Eficaz \\
\hline M5A & 33 & Semelhante & Solteiro & Superior Completo & Diferente & Adaptação Eficaz \\
\hline M5B & 33 & Semelhante & Solteiro & Superior Completo & Diferente & Adaptação Eficaz \\
\hline
\end{tabular}

\section{Quadro 2}

Diagnósticos obtidos pelos gêmeos femininos através da EDAO.

\begin{tabular}{|c|c|c|c|c|c|c|}
\hline Gêmeo & Idade & Aparência & Estado civil & Escolaridade & $\begin{array}{c}\text { Profissão } \\
(=\mathrm{ou} \neq)\end{array}$ & Diagnóstico \\
\hline F1A & 26 & Semelhante & Solteira & Mestrado & Diferente & Adaptação Eficaz \\
\hline F1B & 26 & Semelhante & Solteira & Mestrado & Diferente & Adaptação Eficaz \\
\hline F2A & 37 & Semelhante & Casada & Superior Completo & Iguais & $\begin{array}{l}\text { Adaptação Ineficaz Leve } \\
\text { em crise }\end{array}$ \\
\hline F2B & 37 & Semelhante & Divorciada & Superior Completo & Iguais & $\begin{array}{l}\text { Adaptação Ineficaz Leve } \\
\text { em crise }\end{array}$ \\
\hline F3A & 33 & Semelhante & Solteira & Superior Completo & Diferente & Adaptação Eficaz \\
\hline F3B & 33 & Semelhante & Solteira & Superior Completo & Diferente & Adaptação Eficaz \\
\hline $\mathrm{F} 4 \mathrm{~A}$ & 34 & Semelhante & Divorciada & Superior Incompleto & Diferente & Adaptação Eficaz em crise \\
\hline F4B & 34 & Semelhante & Casada & Ensino Médio & Diferente & Adaptação Eficaz em crise \\
\hline F5A & 37 & Semelhante & Casada & Superior Completo & Diferente & Adaptação Eficaz em crise \\
\hline F5B & 37 & Semelhante & Solteira & Superior Completo & Diferente & Adaptação Eficaz em crise \\
\hline F6A & 27 & $\begin{array}{c}\text { Pouco } \\
\text { semelhante }\end{array}$ & Solteira & Ensino médio & Diferente & Adaptação Eficaz \\
\hline F6B & 27 & $\begin{array}{c}\text { Pouco } \\
\text { semelhante }\end{array}$ & Solteira & Ensino médio & Diferente & Adaptação Eficaz \\
\hline F7A & 25 & Semelhante & Casada & $\begin{array}{l}\text { Superior } \\
\text { Completo }\end{array}$ & Diferente & $\begin{array}{c}\text { Adaptação Ineficaz Leve } \\
\text { em crise }\end{array}$ \\
\hline F7B & 25 & Semelhante & Solteira & $\begin{array}{l}\text { Superior } \\
\text { Completo }\end{array}$ & Diferente & Adaptação Eficaz \\
\hline
\end{tabular}


conseguem demonstrar autonomia e individualidade; entretanto, em suas pesquisas, Bacon verificou que alguns gêmeos demonstram uma busca ativa pela diferenciação e construção da identidade até mesmo em menores idades. A partir dos 12 anos, alguns (F3A e F3B; F6A e F6B; M4A e M4B) alegaram desejar e comprar roupas diferentes do cogêmeo. Isso parece ser um indicativo de que o processo de individualização estava se tornando mais evidente no início da adolescência, demonstrando assim que cada um parecia estar em busca da sua identidade não apenas como uma das características da fase da adolescência, mas também buscando se diferenciar do cogêmeo.

Todos os cogêmeos aqui em questão consideraram que os pais os diferenciavam desde a infância, mesmo que necessitassem recorrer a mecanismos artificiais como pulseiras de identificação, e respeitavam as suas características individuais. Os brinquedos eram de ambos, exceto em um dos pares, em que a propriedade era individual. Chamou a atenção o fato de um dos cogêmeos dizer que os brinquedos eram de ambos, enquanto seu cogêmeo dizia o contrário. Todos os cogêmeos dormiam no mesmo quarto, em camas individuais.

Os cogêmeos de três pares estudaram juntos, tendo se separado, respectivamente, no ensino médio, graduação e pós-graduação; os demais apenas às vezes ficavam na mesma sala, dependo da disponibilidade de turmas nos colégios. De forma geral, todos consideraram adequada a forma com que ficavam nas escolas. Todos disseram que o cogêmeo não influenciou na escolha do curso superior; entretanto, em três dos cinco pares, os cogêmeos consideravam haver semelhanças entre as atividades profissionais.

Na vida adulta, sete dos 10 entrevistados consideravam o cogêmeo como o melhor amigo; os cogêmeos de um dos pares consideravam o relacionamento entre eles como regular e os demais, excelente. Todos os cogêmeos consideraram que seus relacionamentos amorosos foram bons desde a adolescência até o momento das entrevistas.

Verificou-se que, embora se sentissem parecidos e ao longo da vida tenham partilhado muitas vivências, os cogêmeos ressaltavam suas diferenças na maneira de pensar e enfatizavam as buscas pela diferenciação, especialmente a partir da adolescência. Seguem alguns exemplos.

F1A e F1B: 25 anos, aparência semelhante, solteiras, ambas com o mesmo curso superior; exercem cargos administrativos. Foram amamentadas juntas até os qua- tro anos de idade. Eram identificadas por pulseirinhas. Atualmente, ambas opinam sobre o vestuário da cogêmea: “Os mesmos gostos, nós somos bem parecidas nisso, porque fisicamente nós somos iguais, mas nós temos pensamentos diferentes, formas de agir, só que os gostos pras coisas, a gente gosta das mesmas coisas, eu e ela" (F1A).

F3A e F3B: 37 anos, aparência semelhante, ambas solteiras, curso superior completo, profissões diferentes. Quando crianças, os pais utilizaram brincos diferentes para facilitar a identificação, usavam roupas iguais com cores diferentes e, na adolescência, passaram a buscar roupas diferentes. Residem em cidades diferentes, mas conversam diariamente. "Na infância como se nós fossemos uma pessoa só. Na adolescência, a gente tentava ser o mais diferente possivel, pra justamente ter distinção. Atualmente somos pessoas diferentes" (F3B).

F6A e F6B: 27 anos, aparência pouco semelhante, ambas solteiras, ensino médio completo, profissões diferentes. Nasceram com tempo gestacional diferente - nove e oito meses, pesando três e um quilo e meio, respectivamente. Sempre foram percebidas de forma diferente pela família. Durante a infância, eram vestidas com os mesmos modelos mas cores diferentes. Os brinquedos eram propriedade de ambas. Atualmente residem e trabalham em cidades diferentes, mas estão sempre juntas nas reuniões familiares e, ocasionalmente, no lazer.

M4A e M4B: 28 anos, aparência semelhante, ambos casados, escolaridade superior incompleto e o cogêmeo, superior completo; profissões diferentes. Os brinquedos eram de ambos e muitas vezes duplicados - dois brinquedos iguais. Até os 18 anos, os amigos eram os mesmos; começaram a ter alguns diferentes ao começarem a trabalhar. Consideram o cogêmeo como o melhor amigo.

Os pais os diferenciavam desde o início: um deles era mais "gordinho" e tinha uma "pinta"; entretanto, as demais pessoas da família os confundiam. $\mathrm{Na}$ atualidade muitas vezes não são identificados pelas pessoas. Esses cogêmeos foram vestidos de forma idêntica na infância e na adolescência, mas os próprios gêmeos começaram a comprar roupas com pelo menos cores diferentes. Na infância havia apenas um guarda-roupa comum. A princípio, a mãe determinava as roupas do dia, depois eles próprios escolhiam, embora colocassem modelos iguais:

A maioria era roupa dos gêmeos, era um guarda-roupa pros dois, cada um tinha sua roupa ali 
mas, na verdade, era tudo igual, a cor era igual, ou o modelo era igual, às vezes mudava alguma coisa, mas era sempre no mesmo padrão ali (M4A).

Na maior parte do tempo estudaram juntos, mas em algumas séries, separados em função da bagunça que faziam juntos na escola.

Boa parte do que a gente estudou foi junto. Na segunda série teve que separar porque o professor não aguentava os dois juntos (M4A)

[...] gêmeo sempre chama atenção né, querendo ou não, e na época, como a gente fazia muita bagunça na escola, tava no meio sempre da bagunça, né. Hoje poderia ser diferente, já que, se não fosse gêmeos, não teria essa ligação, tanto que não estaria no mesmo ano, nunca estaria na mesma classe... (M4B).

Houve uma situação inusitada, que contraria a ideia dos autores que recomendam a percepção e o respeito pelas características individuais (Reis, 2015; Winnicott, 1964/1982):

Meu irmão repetiu na segunda série. Olha pra você ter ideia, aí que minha mãe fez, foi lá e me repetiu, só pra ficar junto, isso eu fui descobrir depois, meu pai quase matou ela, aí a gente continuou estudando junto (M4B).

Trabalharam juntos por alguns meses durante a adolescência, mas ambos consideram que não deu certo. Na adolescência, interferiam nas escolhas amorosas. A participação conjunta nas reuniões familiares é ocasional, muito pouca no trabalho e no lazer. Percebe-se que, embora considerem o cogêmeo como o melhor amigo, ambos mantêm vida bastante individualizada.

M5A e M5B: 33 anos, aparência muito semelhante, solteiros, ambos possuem curso superior completo, profissões diferentes em áreas correlatas. Quando crianças, eram diferenciados por "pinta" em um dos cogêmeos, mas um deles relatou:

Minha mãe, ela sabia, às vezes, só quando a gente está de costas que ela confunde. Ou, às vezes, quando ela está com raiva e chama um primeiro, chama qualquer um lá e o que aparecer ela fala "vai você mesmo". Mas minha mãe e meu pai nunca tiveram problema pra identificar, acho que só quando a gente está de costa ou meio de lado que ela não conseguia identificar e chamava (M5A).

Cada um tinha os próprios brinquedos, exceto a bicicleta, que era única, e os partilhavam nas brincadeiras. Quando começaram a trabalhar, compravam as próprias roupas e um usava as roupas do outro. Atualmente consideram que os estilos são parecidos; um deles chegou a afirmar:

Sim, tanto eu quanto ele, hoje a gente está muito parecido, então com roupa, os mesmos gostos, nossa, é muito difícil dele comprar alguma coisa que eu não goste e é muito difícil de eu comprar alguma coisa que ele não gosta ...

$\mathrm{Na}$ maior parte do tempo compartilhavam a mesma sala de aula e se separaram ao cursar a faculdade. Muitas vezes não eram identificados pelos professores e se "um fizesse bagunça, a professora chamava a atenção dos dois". Fizeram curso profissionalizante juntos. As amizades, atividades escolares, de esporte e lazer foram partilhadas até a adolescência; na vida adulta participavam juntos de festas familiares e atividades de lazer, exceto quando um deles tem atividades específicas com a noiva. Na vida adulta, ambos consideram o cogêmeo como o melhor amigo. Ambos se consideram muito parecidos em vários aspectos; entretanto, quanto às escolhas amorosas, consideram haver diferenças significativas, denotando o rompimento da simbiose entre eles.

Verificou-se que os cogêmeos dos cinco pares diagnosticados com Adaptação Eficaz conseguiram se individualizar a ponto de exercerem profissões diferentes e conseguirem estabelecer relacionamentos afetivos duradouros. Os seguintes aspectos parecem ter contribuído de forma significativa para o desenvolvimento da individualização:

$\left.1^{\circ}\right)$ todos eram identificados pelos pais desde o início da vida, utilizando, quando necessário, recursos artificiais (roupas diferentes, pulseiras, brincos etc.), tal qual recomendado por alguns autores, como Viotto (1999), por exemplo;

$2^{\circ}$ ) os próprios cogêmeos buscaram formas de se diferenciarem usando vestuários diferentes, principalmente na adolescência, provavelmente para assumir uma aparência que facilitasse a identificação de cada um pelas outras pessoas. 
Este fato corrobora os resultados encontrados em pesquisa de Cerruti et al. (2008) em que os gêmeos univitelinos buscavam se diferenciar inclusive nos desenhos que faziam de si próprios e dos cogêmeos.

\section{Ambos os cogêmeos de cada par diagnosticados com Adaptação Eficaz em crise}

Em três pares (F4A e F4B; F5A e F5B; M2A e M2B), ambos os cogêmeos foram diagnosticados com Adaptação Eficaz em crise, sendo dois pares femininos e um par masculino. Os gêmeos assim diagnosticados apresentaram respostas que denotavam integração nos diversos sistemas e coerência em suas ações, mas naquele momento encontravam-se em crise motivada por dificuldades em algum setor de suas vidas. Os cogêmeos de cada par tinham aparência semelhante; em um dos pares (M2A e M2B) o estado civil era igual e em um dos pares (F5A e F5B) o nível de escolaridade era igual; e nos demais, diferente (Quadro 1 e 2).

F4A e F4B: 34 anos, sexo feminino, aparência semelhante, uma divorciada e outra casada, uma com curso superior e a cogêmea com ensino médio, profissões diferentes embora na mesma área. Ambas se consideraram muito ansiosas, com dificuldade em confiar nos relacionamentos e em controlar as próprias emoções em situações de emergência ou stress no trabalho. Em muitas falas pareciam ter copiado as respostas entre si.

Os pais conseguiam diferenciá-las, mas as demais pessoas as confundiam. Durante a infância e adolescência, eram vestidas de forma idêntica; na vida adulta, os estilos são semelhantes e algumas roupas iguais. Uma das cogêmeas considerou que os pais as tratavam como se fossem iguais, enquanto a cogêmea sentia que sua individualidade era respeitada. Os brinquedos eram propriedade de ambas. Quanto à escolaridade, uma das cogêmeas foi reprovada na $3^{\mathrm{a}}$ série do curso Fundamental e, então, passaram a frequentar classes diferentes; assim, esta cogêmea disse que passou a ter alguns amigos diferentes enquanto a outra alegou que continuavam com amigos em comum. Ambas consideram a cogêmea como a melhor amiga. A cogêmea F4B ficou um ano fora da escola, então, no curso Médio, voltaram a estudar juntas; posteriormente, uma cursou Ensino Superior. Participavam juntas das atividades de esporte e apenas uma delas mencionou que trabalharam juntas. Atualmente compartilham eventos familiares e de lazer. Enquanto a divorciada considera a cogêmea sua melhor amiga, a outra considera o esposo.

É possível conjecturar que o processo de individualização em F4A pode ter se estabelecido de forma mais precária, pois considera que F4B interfere na sua vida e a trata como se fosse ainda adolescente, enquanto a cogêmea não menciona qualquer interferência.

F5A e F5B: 37 anos, aparência semelhante; F5A vive em união estável há poucos meses e F5B é casada há mais de 10 anos; escolaridade superior com especialização, profissões diferentes. Ambas apresentaram dificuldade de sono, de lidar com frustrações, ansiedade e alimentação inadequada. Em muitas falas parecem ter copiado as respostas entre si.

Ambas relataram que eram tratadas de forma semelhante e diferenciadas por uma pinta facial de uma delas, usavam o mesmo berço e roupas idênticas. Geralmente as pessoas não conseguiam diferenciá-las. Uma das cogêmeas disse que, quando bebê, chegava a ficar com fome, pois a mãe dava mamadeira apenas para a cogêmea acreditando ter alimentado a ambas. A cogêmea não mencionou este fato mas enfatizou a confusão vivenciada pela mãe.

Eram quatro crianças, só tinha um ano de diferença de cada uma, eu e ela e mais as outras duas irmãs. Então minha mãe acordava de noite, dava mama pra uma, pra quem estava chorando, na sequência, eram quatro, e ela achava que dava mama pra mime eu chorava, chorava, chorava, chorava, e ela me levou no médico e o pediatra falou: "é fome". Ela dava de mamar para a F5B. A F5B, não contente, continuava chorando e eu dormia, então eu não mamava, a F5B mamava por mim (F5A).

Ambas se consideram muito unidas. Embora tenham curso superior em áreas distintas, trabalham no mesmo local e moram em casas individuais, no mesmo quintal.

Eu falo assim que é uma ligação que quem não é gêmeo não tem noção, não tem como descrever, é uma ligação, parece que é coisa de corpo, não consigo te dar palavras sobre isso (F5A).

É estranho e legal, [...] às vezes, eu olhava pra ela, a gente sempre olha pra uma pessoa, um irmão, mas, às vezes, eu olhava e pensava: meu deus, sou eu, igual. Dá um negócio estranho, divertido; era legal (F5B). 
Disseram que preferiam usar roupas iguais, mesmo que com cores diferentes. Ainda compram roupas iguais, mas atualmente preferem cores diferentes.

A gente fazia questão de ser igual. Minha mãe não obrigava, a gente que fazia questão, só pra causar tumulto mesmo. A gente sempre se sentiu bem, era muito engraçado, as pessoas andando, olhavam de lado, a gente se matava de rir. Ou enganar as pessoas, nossa senhora (MFY1B).

Uma das cogêmeas disse que os brinquedos eram iguais mas cada uma tinha o seu e a outra disse que eram de ambas. Ambas consideram a cogêmea como a melhor amiga. Na escola, geralmente ficavam juntas, mas, por vezes, separadas em função de bagunça: faziam prova no lugar da outra, entre outras traquinagens. Se separaram no Ensino Superior. As atividades de esporte eram realizadas juntas.

Quanto aos relacionamentos afetivos, embora entrevistadas separadamente, ambas admitem sorrindo que já chegaram a trocar de namorados e/ou uma cogêmea sair com o namorado da outra, fato este mencionado por alguns autores, como Bittencourt e Bittencourt (1999) por exemplo, ao descrever as histórias de vida de gêmeos. Na atualidade, ambas mantêm relacionamentos afetivos estáveis.

Ao analisar a maneira como ambas se relacionam, parece haver uma dependência recíproca, embora apresentem Adaptação Eficaz, uma vez que ambas fazem questão de estar próximas em todos os aspectos, inclusive no trabalho e moradia, mesmo mantendo relacionamentos afetivos duradouros.

É porque a ligação é estranha, é tipo aquilo que falei, eu estou fora do meu corpo e ela está fora do dela. Se ela não estiver perto, eu não me sinto bem, entendeu? É muito estranho isso (F5A).

M2A e M2B: 31 anos, masculino, aparência semelhante, ambos solteiros, escolaridade superior e superior incompleto, profissões diferentes. Ambos possuem problemas emocionais, dificuldade em manter relacionamentos e confiar nas outras pessoas.

A mãe os identificava desde pequenos, mas o pai até hoje não consegue saber quem é quem. Afirmam categoricamente que o vestuário na infância era sempre diferente, pelo menos nas cores. Na vida adulta, acontece de, sem planejamento prévio, usa- rem roupas iguais. Um deles afirmou que o vestuário é "básico", com os mesmos modelos. Dormiam no mesmo quarto, em camas individuais até os 18 anos. Atualmente residem na mesma casa em quartos separados. Participam juntos das atividades familiares e de lazer. Estudaram juntos até a oitava série, quando um deles foi reprovado.

A gente só separou porque a gente mudava muito de cidade, e ele reprovou. Isso foi na oitava série. Mas sempre junto, jamais separava, era revolta quando separava [...] a gente era o capeta. Não tava nem aí, nem ligava, era uma zona, meus pais viviam mais na escola que a gente (M2A).

Ambos apresentam dificuldade em manter relacionamentos afetivos. Por outro lado, enfatizam o quanto são unidos e apreciam realizar atividades conjuntas. Fica a impressão de viverem uma relação afetiva narcísica como se buscassem no cogêmeo a relação com um ser igual e/ou consigo mesmo. Provavelmente não conseguem se vincular afetivamente a outras pessoas por manter ainda um vínculo simbiótico com o respectivo cogêmeo. Isso corrobora a ideia de Marquez (2010, p. 90), ao considerar que o aprisionamento narcísico verificado nos gêmeos indiferenciados poderia impedir o "processo de direcionamento da libido para o ego ideal e, consequentemente, para a caracterização de um ideal sexual" que garantiria a triangulação edípica bem como a estruturação do Eu.

Quanto à perseverança em seus relacionamentos amorosos afirmaram: "nossa, as questões amorosas pra mim eram tudo uma desgraça... Já desisto logo, não tenho paciência não" (M2A); "desisto fácil. Dois palitos e desisto" (M2B).

Embora ambos tenham sido diagnosticados com Adaptação Eficaz em crise, um dos cogêmeos encontrava-se desempregado e feliz. Considerando já ter 32 anos, pode-se questionar se realmente estaria vivenciando apenas uma situação passageira de crise na profissão e/ou se a simbiose entre ambos seria tamanha a ponto de um se amparar no outro nestes momentos e por isso sentir-se seguro, demonstrando que a estabilidade emocional e profissional de fato seria dependente do apoio do cogêmeo.

Pelo menos um aspecto dos gêmeos diagnosticados com Adaptação Eficaz em crise chamou a atenção: nem sempre eram diferenciados pelos pais desde o início da vida. Esse fato pode ter contribuído 
negativamente para o processo de individualização e também para a vivência de situações de crises emocionais ao longo da vida adulta. Vieira e Branco (2010) afirmam que as crenças e expectativas a respeito dos gêmeos implicam estratégias de canalização cultural que podem facilitar ou dificultar o "processo de construção ativa da individuação e subjetivação dos gêmeos" (p. 589), sendo que, no caso destes gêmeos, contribuíram de forma a dificultar a adaptação à vida adulta. Ficou a impressão de que, embora tenham sido diagnosticados com Adaptação Eficaz de acordo com a EDAO-R (Simon, 2005), trata-se de uma adaptação fugaz por depender da presença e apoio constantes do cogêmeo.

\section{Ambos os cogêmeos de cada par diagnosticados com Adaptação Ineficaz Leve em crise}

Apenas o par F2A e F2B apresentou o mesmo diagnóstico na EDAO - Adaptação Ineficaz Leve em crise.

F2A e F2B: 37 anos, aparência muito semelhante, uma casada e a cogêmea divorciada; ambas têm a mesma profissão e cursam pós-graduação em nível stricto sensu. Sempre foram tratadas da mesma forma, usando roupas iguais até os 15 anos.

A vida inteira como se fosse uma só pessoa. $\mathrm{Na}$ infância, engraçadinho né, são gêmeas. Vestíamos as mesmas roupas ate 15 anos de idade. Isso foi ruim pra nós né. Não construímos uma identidade própria. A família se referia nunca com os nomes, sempre as meninas, as gêmeas, as irmãs. (F2A).

Ambas consideram que não foram respeitadas em suas individualidades e precisaram se unir para lutar pela vida, mesmo no interior do lar, respondendo da seguinte maneira quanto ao respeito pelas próprias individualidades: "Nunca. Iguais, não eram respeitadas" (F2A). "Não, de forma alguma. Foram negadas. Eu fui sempre sufocada e, ao mesmo tempo que a F2A foi minha companheira, ela proibiu que eu crescesse. Ela proibiu que eu me desenvolvesse" (F2B).

Os brinquedos eram propriedade de ambas e elas geralmente tinham as mesmas amizades. Dormiam na mesma cama até os 24 anos; a partir dos 12 partilhavam uma cama de casal. Sempre estudaram juntas, inclusive na pós-graduação. Ambas afirmaram que as pessoas as tratam de forma igual, chegando a fazer brincadeiras consideradas de mau gosto por uma das cogêmeas, tais como: "quem é a verdadeira e quem é a falsa?" Afirmaram que as amizades são muito superficiais e que a cogêmea era a melhor companheira. Enquanto uma considera que a cogêmea interfere na vida profissional e acadêmica, a outra considera que há influência em todas as áreas. Ambas se consideram bastante parecidas:

Somos autoritárias nas relações, somos parecidas em tudo, nos gostos, nos estilos, eu sei quando ela tá triste, quando ela tá feliz, quando ela tá animada, eu conheço a F2A mais do que qualquer outro ser humano, assim como ela me conhece também. (F2B).

Embora ambas tenham conseguido estabelecer relacionamento afetivo e até constituído casamento, relataram grandes dificuldades. O processo de individuação ocorreu, até certo ponto; entretanto, o fato de partilharem as mesmas atividades de estudo, profissão e amizades levou a conjecturar que o vínculo simbiótico continuava muito intenso e contribuiu para que a Adaptação Ineficaz Leve em crise na verdade seja utópica. Fica a impressão de que necessitam da presença da cogêmea para a manutenção da aparente saúde mental, possivelmente motivada pela necessidade de se defender do mundo em função de falhas na função materna, que não deve ter ocorrido de forma suficientemente boa, conforme a fala de uma das cogêmeas: "Tivemos que nos unir muito pra cuidar dos nossos irmãos, já que meus pais se separaram. Então, muito cedo eu e F2A tivemos que amadurecer e criar uma responsabilidade domestica" (F2B).

É possível conjecturar que o fato de terem sido percebidas e tratadas de forma tão parecida, inclusive utilizando o mesmo vestuário por 15 anos pode ter contribuído para as dificuldades encontradas na vida adulta. Fica a impressão de que necessitam manter a simbiose a fim de evitar o caos, como se a vivência individualizada pudesse favorecer o sucesso da cogêmea ou até a morte de si mesma.

\section{Diagnóstico adaptativo diferente nos cogêmeos de cada par}

Em três pares (M1A e M1B; M3A e M3B; F7A e F7B), os resultados obtidos na EDAO foram diferentes, sendo dois masculinos e um feminino. Os cogêmeos de dois pares possuem profissões distintas e o terceiro par trabalha na mesma função e local. Pelo menos um dos cogêmeos de cada par possui relacionamento afetivo estável. 
M1A e M1B: 40 anos, aparência pouco semelhante, ambos casados, ambos concluíram o Ensino Médio, trabalham na mesma profissão e local. O diagnóstico EDAO foi diferente, sendo o primeiro Adaptação Eficaz em crise e o segundo Adaptação Ineficaz Leve em crise. Ambos apresentaram problemas emocionais atuais, um deles queixou-se de ansiedade e o segundo de sintomas depressivos.

Consideraram-se fisicamente bem parecidos e com diferenças na maneira de ser. Na adolescência chegaram a usar os documentos de identificação do cogêmeo. Ambos consideram que foram respeitados em suas individualidades desde a infância pela mãe e avó, pelas quais foram criados. Os brinquedos eram individualizados, mas os amigos na infância eram os mesmos. Ambos não se recordavam até quando estudaram na mesma sala: um deles achava que foi até a $7^{\text {a }}$ série do Fundamental, entretanto o colégio era o mesmo. Cada um afirmou que o cogêmeo se sobressaía na escola.

M1A demonstra levar a vida independente do cogêmeo, exceto nas relações profissionais, e considera 0 relacionamento deles ruim, enquanto $B$ demonstra uma certa insatisfação decorrente das desavenças profissionais entre ambos, mas considera o cogêmeo como seu melhor amigo. M1B relatou que até as escolhas amorosas aconteceram a partir dos relacionamentos vivenciados nos grupos de amigos e atividades sociais de que participavam juntos. Entretanto, na ocasião da coleta de dados, conviviam apenas no local de trabalho.

M1A considera ter uma boa autoestima enquanto seu cogêmeo assim se descreve:

[...] nervoso demais, ansioso, meio briguento, de pouca calma, cara fechada, não gosto muito de sair, não gosto muito de pescar, não gosto de beber, mas estou procurando melhorar.

Na vida adulta ambos se consideraram bastante diferentes " no modo de se comportar e de ser" (M1A). A maneira como um considera a interferência do outro em sua vida foi interessante e, ao mesmo tempo fornece alguma ideia de como ambos se relacionam:

Meu irmão gosta de interferir nas minhas relações amorosas e no meu convívio com minha mãe e vó (M1A).

[M1A] Interferiu de uma maneira positiva, porque meu irmão estava do meu lado ali até praticamente seus vinte e tantos anos, praticamente todo dia, a gente morava na mesma casa, no mesmo quarto, interferiu de uma maneira positiva no dia a dia de tudo que a gente fazia. Depois, na parte adulta, cada um montou a sua família, mas a gente continua trabalhando junto, interferiu também na parte de trabalho, mas uma interferência positiva (M1B).

M3A e M3B: 37 anos, aparência pouco semelhante, sendo um casado e o outro solteiro, com escolaridade e profissões diferentes. Diagnosticados como Adaptação Eficaz e Adaptação Eficaz em crise. Eram vestidos de forma idêntica até a adolescência, mas na vida adulta o vestuário tem estilos diferentes. Quanto à tal prática, afirmaram: "Roupas iguais. Frustrado" (M3A), "Isso anula na individualidade de cada um" (M3B).

Ambos consideram que suas características individuais eram respeitadas pelos pais. Na infância os brinquedos eram dos gêmeos, embora em ocasiões especiais ganhassem objetos distintos e brincavam juntos. Os amigos na infância eram os mesmos. Estudaram juntos até o final do curso Fundamental; no Ensino Médio um deles foi reprovado e, então, passaram a frequentar salas distintas. Posteriormente ambos participaram de cursos relativos à formação religiosa, que foi concluída apenas por um deles.

Até o início da vida adulta, ambos participavam de atividades comuns em diversas áreas. Mais tarde se individualizaram e seguiram caminhos distintos; atualmente participam juntos apenas dos eventos familiares. Ambos consideram o cogêmeo como seu melhor amigo, entretanto M3B enfatiza nem sempre sentir-se compreendido pelo irmão em função de suas convicções e formação profissional religiosa.

Mas é meu irmão, existem coisas na minha vida profissional que ele não sabe, ele não pode saber por causa do sigilo do fenômeno religioso, da ética profissional. Mas a gente tem uma ligação muito forte, o fato de sermos gêmeos potencializa (M3B.)

O cogêmeo (M3A) utiliza muitas explicações racionais para suas atitudes em vários aspectos da vida, denotando uso abusivo de mecanismos de defesa, talvez para justificar a si mesmo que se encontra bem-adaptado ao modo de vida escolhido, mas que talvez ainda esteja buscando o autoconhecimento e as verdades sobre si mesmo. 
F7A e F7B: 25 anos, aparência semelhante, a primeira é casada e a segunda solteira (noiva); possuem o mesmo curso superior completo mas atuam em profissões diferentes. O diagnóstico via EDAO foi Adaptação Ineficaz Leve em crise e Adaptação Eficaz. Ambas apresentaram dificuldades de sono e F7A, queixas de gastrite, nervosismo, impaciência e ansiedade.

Ambas alegaram que, quando pequenas, a mãe as confundia e chegou a alimentar duas vezes a mesma criança. A mãe as diferenciava pelo fato de uma ser mais bochechuda que a outra, mas também usava pulseiras para facilitar a identificação. Foram vestidas de forma idêntica até os oito anos e atualmente usam o mesmo estilo. Ambas consideram que suas características individuais sempre foram respeitadas pela mãe.

A maneira como cada cogêmea descreveu sua história de vida foi no mínimo interessante. A percepção de cada uma sobre vários assuntos foi diferente, demonstrando possivelmente aspectos especiais no processo de individualização vivenciado.

Segundo F7A, os brinquedos eram de ambas mas a cogêmea disse que eram individuais. Foi interessante perceber como F7A disse que estudaram juntas até a $4^{\mathrm{a}}$ série do Fundamental e depois sempre separadas, enquanto a cogêmea disse que nunca estudaram juntas. Curiosamente, estudaram juntas na faculdade, pois fizeram o mesmo curso. Mesmo estudando em salas separadas, havia ajuda mútua na realização de tarefas escolares, mas os trabalhos em equipe eram feitos com os respectivos colegas de sala. F7A descreveu peripécias e travessuras realizadas tanto na escola como em situações de lazer realizadas junto com a cogêmea, ressaltando o quanto eram parceiras. Embora F7B considerasse que atividades de esporte e lazer fossem partilhadas com a cogêmea, disse ter sido influenciada pelo irmão quanto às atividades esportivas. F7B disse que nunca realizaram atividades profissionais juntas, enquanto a cogêmea ressaltou as atividades desenvolvidas durante a graduação.

Quanto às amizades, ambas consideram que havia amigos em comum e outros separados. Ambas alegam ter amizade com a cogêmea, mas não a consideram como "a melhor amiga". Assim descreveram o relacionamento com a cogêmea:

As duas têm temperamento forte, eu sou brava e minha irmã é muito mais brava. Então, se você fala alguma coisa que ela não gostou então atravessa e ela já dá no meio, entendeu, então a bichi- nha é brava! [... mas a gente nunca ficou assim sem se falar "eu não tenho mais irmã". Isso aí a gente nunca fez (F7A).

Bom com alguns conflitos, mas nada que passa cinco minutos e já tá tudo certo [.... Se eu e ela brigamos e eu opto por ficar quieta, ela sabe o que eu tô pensando. Ela diz: Você queria dizer isso, isso e isso, né? E queria. Apesar de achar que somos muito diferentes, pensamos muito igual (F7A).

Ambas consideraram que a escolha do curso superior foi influenciada pelo irmão. Atualmente participam juntas de reuniões familiares, atividades esportivas e lazer, enquanto as atividades profissionais são em áreas distintas, apenas uma delas exerce a profissão relativa ao curso de graduação.

$\mathrm{Na}$ vida adulta, consideram-se "diferentes"; entretanto, F7A chegou a afirmar:

A gente muitas vezes tava andando na rua, já aconteceu muitas vezes, as pessoas vêm e cumprimentam e eu sou educada, eu cumprimento. Daí eles falam com minha irmã: "te encontrei e você foi tão fria comigo", porque eu sou assim: se eu não conheço, eu meio que crio o escudo, entendeu? Eu vou cumprimentar, mas é diferente se eu tivesse uma amizade com você, entendeu? É diferente. Depois que eu vou conhecendo a pessoa, depois que eu vou adquirindo essa amizade. Então as pessoas falam: "ah, uma é mais fechada, a outra é mais retraída", então tem disso, entendeu? Então as pessoas: "eu te cumprimentei e você nem olhou na minha cara, nem falou comigo direito, parecia que nem me conhecia", então a gente fala: "acho que era minha irmã". Então rola bastante disso.

Embora tenham apresentado percepções diferentes sobre a maneira como ocorreu a história de vida de cada uma, percebe-se que ainda hoje mantêm-se muito unidas. O processo de individualização possibilitou que cada uma seguisse uma profissão específica e estabelecesse relacionamentos afetivos duradouros.

Verificou-se nestes casos que os cogêmeos mantinham laços afetivos bastante significativos e, em um dos pares, ambos trabalhavam na mesma empresa. Todavia, todos desenvolveram suas individualidades de forma aparentemente saudável. 
Aspecto que se destacou nestes três pares de gêmeos: todos os cogêmeos afirmaram que suas características individuais foram respeitadas pelos pais, mesmo naquele par em que a mãe chegou a amamentar o mesmo bebê em detrimento do outro. Ou seja, apesar de as confusões que uma das mães possa ter vivido ao cuidar dos bebês gêmeos, conseguiu encontrar maneiras de diferenciá-los e tratar cada um de forma única. Esse fato endossa a recomendação dos estudiosos, que enfatizam a necessidade de os pais perceberem e respeitarem as características individuais dos gêmeos (Dorneles, \& Schimdt, 2015; Reis, 2015; Winnicott, 1964/1982).

O processo de individualização parece ter ocorrido de forma mais eficiente do que nos demais pares, a ponto de os cogêmeos apresentarem diagnósticos adaptativos diferentes, denotando características próprias a cada um. É possível que a problemática emocional que os afetava, levando-os à vivência de crise em cinco dos seis cogêmeos, seja independente da questão da gemelaridade em si, uma vez que as questões emocionais que os afligiam aparentemente envolviam mais aspectos específicos de cada um do que decorrentes do relacionamento com o cogêmeo.

Verificou-se nestes casos que os cogêmeos mantinham laços afetivos fraternos bastante significativos - inclusive, os cogêmeos de um dos pares trabalhavam na mesma empresa; entretanto, todos desenvolveram suas individualidades de forma aparentemente saudável.

\section{Considerações finais}

O processo de individualização dos gêmeos é complexo e ainda pouco compreendido. Todavia, a maneira como os pais identificam os cogêmeos, buscam perceber as características próprias de cada um e atender às necessidades individuais desde o início da vida parece ser $\mathrm{o}$ aspecto mais significativo para favorecer o processo de individualização. De forma geral, os cogêmeos entrevistados que foram identificados e respeitados em suas individualidades desde a infância conseguiram desenvolver identidades próprias e adaptar-se à vida de forma mais independente, tanto nos aspectos emocionais quanto profissionais.

A prática, ainda comum, de vesti-los com os mesmos trajes dificulta a identificação e provavelmente deve interferir negativamente no processo de individualização, embora de forma não decisiva, pois na adolescência a grande maioria buscava outras alternativas, reivindicando ou adquirindo roupas diferentes.

Chamou a atenção também o fato de alguns cogêmeos apresentarem percepções diferentes sobre os momentos partilhados ao longo da vida, denotando que a maneira como cada um vivencia e elabora é mais importante do que o fato de ambos terem passado pela mesma situação. Tais fatos corroboram as ideias de outros autores (Määttä et al., 2016), que chamam a atenção para a necessidade de ouvir os gêmeos para melhor compreender a evolução da identidade em cada um, pois, mesmo sendo educados de forma semelhante e nos mesmos ambientes, desenvolvem-se com características específicas e, logo, como indivíduos diferenciados.

Finalmente, ao serem solicitados a dar sugestões sobre como conduzir a educação dos gêmeos, foram unânimes em afirmar: tratar os cogêmeos como pessoas diferentes e procurar perceber as características individuais de cada cogêmeo. Aliás, foi o fator preponderante encontrado neste trabalho como um diferencial entre os cogêmeos que mantinham um relacionamento simbiótico e os que conseguiram se individualizar de forma mais saudável. A realização de novas pesquisas a respeito das implicações dos cuidados parentais no processo de individualização $d o$ ponto de vista dos gêmeos se faz necessária, considerando que as vicissitudes pertinentes à gemelaridade são diferentes daquelas vivenciadas pelos indivíduos que nascem sozinhos.

\section{Referências}

Andrade, L., Martins, M. M., Angelo, M., \& Martinho, J. (2014). A saúde mental na parentalidade de filhos gémeos: revisão da literatura. Revista Portuguesa de Enfermagem de Saúde Mental, (n spe 1), 109-116. Recuperado de http://www.scielo.mec.pt/scielo.php?script=sci_arttext\&pid=S1647-21602014000100018

Athanassiou, C. (1986). A study of the vicissitudes of identification in twins. International Journal of Psycho-analysis, 67(3), 329-335.

Bittencourt, A., \& Bittencourt, I. (1999). Gêmeos, semelhança oculta. Uberaba, MG: Vitória. 
Cerrut, G., Prino, L. E., \& Quaglia, R. (2008). La imagen de si mismos que tienem los niños gemelos a través de los dibujos. INFAD Revista de Psicologia, (1), 91-100. Recuperado de http://infad.eu/RevistaINFAD/2008/n1/volumen1/INFAD_010120_91-100.pdf

David, D. L., Azevedo, E. C., Russi, E. M. S., Berthoud, C. M. E., \& Oliveira, A. L. (2000). Tríade de contato íntimo: apego entre mãe e filhos gêmeos. Revista Biociências, 6(1), 57-63. Recuperado de http://periodicos.unitau.br/ ojs-2.2/index.php/biociencias/article/viewFile/29/12

Dorneles, C. P., \& Schimdt, V. Z. (2015). Relação materna na construção da identidade de gêmeos. Revista de Psicologia da IMED, 7(2), 48-57. https://doi.org/10.18256/2175-5027/psico-imed.v7n2p48-57

Honda, G., \&Yoshida, E. M. P. (2013). Mudança em psicoterapia: indicadores genéricos e eficácia adaptativa. Estudos de Psicologia (Natal), 18(4), 589-97. https://doi.org/10.1590/S1413-294X2013000400006.

Määttä, K., Päiveröinen, H., Määttä, R., \& Uusiautti, S. (2016). How did I become me? Identical female twins describe the development of their individuality. Journal of Educational and Developmental Psychology, 6(2), 37-46. https://doi.org/10.5539/jedp.v6n2p37

Marquez, I. M. A. B. (2010). Gêmeos, subjetividade e narcisismo: Especificidades interferentes. São Paulo, SP: Escuta.

Reis, M. E. B. T. (2015). Bebês gêmeos: Relacionamento afetivo e cuidados parentais. Curitiba, PR: Juruá.

Santos, M. C., Honda, G. C., Santeiro, T. V., \& Yoshida, M. P. (2013). Eficácia adaptativa: produção científica brasileira (2002/2012). Contextos Clínicos, 6(2), 84-94. https://doi.org/10.4013/ctc.2013.62.02

Scalco, M. O., \& Donelli, T. M. S. (2014). Os sintomas psicofuncionais e a relação mãe-bebês gêmeos aos nove meses de idade. Temas em Psicologia, 22(1), 55-66. https:// doi.org/10.9788/TP2014.1-05

Simon, R. (1989). Psicologia clínica preventiva: Novos fundamentos. São Paulo, SP: EPU.

Simon, R. (1997). Proposta de redefinição da E.D.A.O. (Escala Diagnóstica Adaptativa Operacionalizada). Boletim de Psicologia, 47(107), 85-94.

Simon, R. (2005). Psicoterapia breve operacionalizada: Teoria e técnica. São Paulo, SP: Casa do Psicólogo.

Simon, R., \&Yamamoto, K. (2009). Psicoterapia breve operacionalizada na clínica privada. Aletheia, (30), 172-182. Recuperado de http://pepsic.bvsalud.org/scielo.php?script=sci_arttext\&pid=S1413-03942009000200014\&lng=pt\&tlng=es

Vieira, A. O. M., \& Branco, A. U. (2010). Iguales, pero diferentes: creencias sociales en la canalización cultural del desarrollo de gemelos. Revista de Psicologia, 28(2), 341-380. Recuperado de http://revistas.pucp.edu.pe/index. $\mathrm{php} / \mathrm{psicologia/article/view/1465/1412}$

Viotto, M. E. B. T. (1999). Conversando sobre gêmeos. Londrina, PR: o autor

Winnicott D. W. (1982). Gêmeos: A criança e seu mundo. Rio de Janeiro, RJ: Koogan. (Original publicado em 1964).

Winnicott, D. (1983). O ambiente e os processos de maturação: Estudos sobre a teoria do desenvolvimento emocional. Porto Alegre, RS: Artes Médicas. (Original publicado em 1963).

Yoshida, E. M. P. (2013). Escala Diagnóstica Adaptativa Operacionalizada de Autorrelato - EDAO-AR: Evidências de validade. Paidéia (Ribeirão Preto), 23(54), 83-91. https://doi.org/10.1590/1982-43272354201310.

Yoshida, E. M. P., Bardagi, M. P., \& Honda, G. C. (2015). Escala da Eficácia Adaptativa (EDAO-AR): Evidências de validade com universitários. Avaliação Psicológica, 14(2), 291-298. Recuperado de http://pepsic.bvsalud.org/scielo. php?script=sci_arttext\&pid=S1677-04712015000200015

Maria Elizabeth Barreto Tavares dos Reis

Docente do departamento de Psicologia e Psicanálise da Universidade Estadual de Londrina (UEL), Londrina - PR. Brasil.

E-mail: bethtavares@uel.br

Sílvia Nogueira Cordeiro

Docente adjunta do Departamento de Psicologia e Psicanálise da Universidade Estadual de Londrina (UEL), Londrina - PR. Brasil.

E-mail: silvianc2000@gmail.com 


\section{Ryad Simon}

Professor Titular do departamento de Psicologia Clínica do Instituto de Psicologia da Universidade de São Paulo (USP), São Paulo - SP. Brasil. Coordenador dos Cursos de Pós-Graduação lato sensu: “Especialização em Psicoterapia Psicanalítica” e "Especialização em Psicoterapia Breve Operacionalizada” a Universidade Paulista. Membro Efetivo da Sociedade Brasileira de Psicanálise de São Paulo.

E-mail: ryad@usp.br

Endereço para envio de correspondência:

Av. Gil de Abreu e Sousa, 2335, casa 227, Jardim Esperança, CEP: 86058-100. Londrina - PR. Brasil.

Recebido 09/11/2016

Reformulado 07/07/2017

Aprovado 17/10/2017

Received 11/09/2016

Reformulated 07/07/2017

Approved 10/17/2017

Recibido 09/11/2016

Reformulado 07/07/2017

Aceptado 17/10/2017

Como citar: Reis, M. E. B. T., Cordeiro, S. N., \& Simon, R. (2018). Diagnóstico adaptativo e individualização em gêmeos: Estudo exploratório. Psicologia: Ciência e Profissão, 38(1), 142-156.

https://doi.org/10.1590/1982-3703004152016

How to cite: Reis, M. E. B. T., Cordeiro, S. N., \& Simon, R. (2018). Adaptive diagnosis and individualization in twins: An exploratory study. Psicologia: Ciência e Profissão, 38(1), 142-156. https:// doi.org/10.1590/1982-3703004152016

Cómo citar: Reis, M. E. B. T., Cordeiro, S. N., \& Simon, R. (2018). Diagnóstico adaptativo e individualización en gemelos: Un estudio exploratório. Psicologia: Ciência e Profissão, 38(1), 142-156.

https://doi.org/10.1590/1982-3703004152016 